\title{
A presença de alunos bolivianos em uma escola do Brasil sob a perspectiva da interculturalidade
}

The presence of Bolivian students in a Brazilian school from the intercultural perspective

Luis Manoel Bezerra ${ }^{1}$; José Licínio Backes ${ }^{1}$

\section{RESUMO}

O artigo tem como objetivo analisar a percepção de professores de uma escola situada na fronteira BrasilBolívia, sobre a diferença linguística dos alunos bolivianos e, sobretudo, se há indícios de que os professores se aproximam de alguma forma da interculturalidade. O campo de análise é a educação intercultural, segundo a qual as diferenças culturais não precisam ser vistas como obstáculos para a aprendizagem, mas como uma riqueza. Para a produção dos dados, os professores da escola foram entrevistados. Observou-se que a maioria dos professores entrevistados percebe a diferença linguística como algo que dificulta a aprendizagem dos alunos bolivianos e que, à medida que os alunos bolivianos aprendem a língua portuguesa, vão conseguindo acompanhar as aulas e os conteúdos.

Palavras-chave: Diferença; Interculturalidade; Fronteira.

\begin{abstract}
This paper aims to analyze how teachers from a school situated at the Brazil-Bolivia border perceive the linguistic difference of Bolivian students and, mainly, whether there is evidence that teachers somehow approximate to interculturality. The field of analysis is intercultural education, according to which cultural differences do not have to be regarded as obstacles to learning, but rather as a strength. Data were produced from interviews of the school teachers. Most of the teachers regard the linguistic difference as something that hinders Bolivian students' learning, and think that the students increasingly succeed in following the classes and contents as they become more proficient in Portuguese language.
\end{abstract}

Keywords: Difference; Interculturality; Border.

\section{CONSIDERAÇõES INICIAIS}

A educação na fronteira tem um grande desafio, pois há ainda muito preconceito em relação a essas regiões: "[...] as pessoas que residem nesses espaços vivenciam a estigmatização, são alvos de preconceito e discriminação dentro do próprio território e sem a realização de deslocamento físico, sofrem uma violência simbólica" (PEREIRA, 2014, p. 98). Além disso, no caso dos brasileiros em relação aos bolivianos, há também a percepção de que esses vêm ao Brasil porque o Brasil é mais desenvolvido e suas escolas têm mais qualidade. Há ainda um outro elemento que interfere nessa relação e no processo educativo que é a diferença linguística e é sobre essa diferença que versa esse

\footnotetext{
${ }^{1}$ UCDB - Universidade Católica Dom Bosco, Campo Grande/MS - Brasil.
} 
artigo. O artigo tem como objetivo analisar como os professores de uma escola situada na fronteira Brasil-Bolívia percebem a diferença linguística dos alunos bolivianos e se há indícios de que os docentes, de alguma forma, se aproximam da interculturalidade, pois entendemos que, embora ela seja importante em todos os contextos brasileiros, em um contexto de fronteira bilíngue, é mais importante ainda. Portanto, o campo de análise é a educação intercultural, segundo a qual as diferenças culturais não precisam ser vistas como obstáculos para a aprendizagem, mas como uma riqueza.

Para alcançar o objetivo, foram entrevistados 12 professores de uma escola situada na fronteira Brasil-Bolívia, mas aqui faremos menção a apenas seis desses professores. As entrevistas foram realizadas no primeiro semestre de 2019 , na escola onde os professores entrevistados atuam. Todos os nomes citados são fictícios.

\section{A EDUCAÇÃO INTERCULTURAL COMO LUGAR DE ANÁLISE}

A educação intercultural nasce na América Latina no contexto dos povos indígenas, em busca de uma educação voltada para a sua cultura, seus conhecimentos e suas identidades. Ela continua sendo uma luta desses povos, e várias são as experiências no Brasil e na América Latina que nela se pautam para construir sua escola específica, diferenciada e bilíngue: "as propostas de trabalho intercultural surgiram principalmente a partir da emergência das identidades indígenas que buscam defender seus direitos" (FLEURI, 2003, p. 21).

As discussões da educação intercultural foram impulsionando autores do campo não indígena a pensarem nela como uma possiblidade de questionamento do racismo, do sexismo e de outros processos de discriminação, como os relativos à nacionalidade. Assim, coloca-se em xeque a educação monocultural/colonial, que caracteriza a educação no Brasil desde o nascimento da educação escolar no período colonial.

Há de se destacar que, segundo a perspectiva intercultural, a escola é um espaço caracterizado pela presença da diferença. Por mais que haja uma história da educação que buscou a padronização e a homogeneização, em certo sentido, com a democratização do acesso à escola, ela tem se tornado cada vez mais marcada pela presença de sujeitos diferentes, culturas diferentes, maneiras diferentes de ver o mundo, formas diferentes de conhecimentos, modos diferentes de viver as sexualidades. Nesse sentido, a escola precisa refletir sobre como lidar "[...] com as diferenças existentes e com as relações de identificação e diferenciação que ocorrem não apenas em seu interior, mas que se estendem externamente, refletindo diretamente nas práticas sociais desenvolvidas pelos sujeitos em suas relações cotidianas" (NUNES, 2011, p. 117).

Candau (1998) destaca que a educação intercultural tem a ver com práticas culturais e modos de vida concretos de seres humanos. A educação intercultural questiona a educação moderna/colonial, que pressupõe a existência de sujeitos humanos abstratos, universais, como se houvesse uma essência humana a ser desenvolvida pela educação. Da ideia de que existe uma essência humana, decorre a noção de que todos os alunos devem ser tratados da mesma forma e devem aprender as mesmas coisas, para que todos consigam desenvolver-se. Dessa forma, a educação intercultural precisa exercer uma vigilância permanente para que não se perca em abstrações, universalizações e essencialismos, baseando-se sempre em um processo de produção não sobre, mas com os sujeitos 
concretos e suas experiências culturais e práticas cotidianas, portanto, como sujeitos implicados, e não como objetos a serem descritos e analisados.

No contexto brasileiro, pensar em uma educação intercultural continua sendo uma tarefa necessária, mas extremamente difícil, pois temos uma história marcada pela eliminação física e simbólica do outro, daquele que não se enquadra no modelo de ser humano imposto pelo ocidente colonizador. "A nossa formação histórica está marcada pela eliminação física do 'outro' ou por sua escravização, que também é uma forma violenta de negação de sua alteridade". (CANDAU, 2002, p. 126).

É essa formação histórica que faz com que a negação do outro sistematicamente esteja presente nas escolas, uma vez que os professores são um efeito desse contexto histórico e cultural que nega a diferença. Portanto, a escola ter surgido exatamente com o objetivo de uniformizar, de criar um Estado-Nação cuja característica considerada imprescindível era ter somente uma língua para poder formar um só povo, uma só cultura, faz com que, mesmo que se tenha a intenção deliberada de desenvolver práticas interculturais, isso não seja algo simples, exigindo que haja um trabalho coletivo e uma reflexão permanente sobre esse processo de uniformização para que, a partir do entendimento de como foi construído, se possa pensar em estratégias de desconstrução da uniformização e afirmação da diferença.

Apesar de não ter conseguido formar um só povo e uma só cultura, o que seria também um problema do ponto de vista da riqueza humana, um desperdício de experiências, como nos diz Santos (2002), esse projeto impulsionou o extermínio, a perseguição, o massacre, a subalternização e a exclusão de grupos e sujeitos diferentes. No Brasil, notadamente, esses grupos são de indígenas e negros; em alguns casos, como em nossa pesquisa, promove-se a discriminação de sujeitos com outra nacionalidade: os bolivianos. Como aponta Fleuri, "na América Latina, a diversidade cultural foi historicamente relegada e deixada à margem das propostas políticas e práticas educativas que, a exemplo do que ocorreu na Europa, se pautaram no ideal homogeneizador do Estado-Nação" (2003, p. 20).

Assim como Candau (2002, p. 135), defendemos uma educação intercultural que procure o diálogo permanente entre as culturas, reconhecendo que sempre haverá tensões, relações de poder, conflitos. Nesse sentido, "[...] privilegiamos a abordagem da educação intercultural, que parte de um conceito dinâmico e histórico da(s) cultura(s), como processo em contínua construção, desconstrução e reconstrução, no jogo das relações sociais presentes nas sociedades".

Cabe destacar também que a educação intercultural não diz respeito somente aos sujeitos que passaram historicamente por processos de subalternização, ainda que eles sejam seus protagonistas. Para que haja efetivamente transformações nas relações entre as culturas, é importante que os sujeitos hegemônicos também sejam afetados pela educação intercultural.

O sujeito hegemônico não possui essência e também é um efeito das relações de poder. Ele pode ser produzido de outra forma por meio da educação intercultural. Obviamente, não se trata de apelar a uma suposta "bondade" do sujeito hegemônico, mas de procurar educá-lo de outra maneira. Todas as identidades, incluindo as hegemônicas, não são fixas, modificando-se continuamente: "as identidades culturais - aqueles aspectos de nossas identidades que surgem de nosso pertencimento a culturas étnicas, raciais, linguísticas, religiosas, nacionais - sofrem contínuos deslocamentos ou descontinuidades." (FLEURI, 2003, p. 23). 
É na luta cotidiana, na tensão permanente, que se produzem outros sujeitos. A educação intercultural pretende afetar todas as relações sociais, desconstruí-las e construí-las em outras bases. Trata-se de um projeto político alternativo que busca modificar as relações vigentes (relações de inferiorização, subalternização, discriminação, hierarquização...) para a reorganização das relações entre as culturas, mediante o diálogo e a comunicação entre elas. A educação intercultural significa outra forma de educar. Se, historicamente, educar teve o significado de acabar com as diferenças e produzir a mesmidade e a homogeneidade, agora passa a significar relacionar-se com a diferença, sem pretensões de aniquilamento, superação ou supressão, mas de aprendizagem recíproca.

Nesse sentido, a crítica à escola monocultural continua sendo tarefa necessária. Como já salientado, Candau (1998) faz a crítica à escola por esta ter sido e continuar sendo um elemento central para o processo de homogeneização cultural e de circulação de um tipo de conhecimento como válido. Ela procura impor normas, conhecimentos e condutas que supostamente seriam de todos, mas a rigor são apenas de um determinado grupo: o grupo hegemônico. A escola é uma das instituições privilegiadas para homogeneizar sujeitos. Para romper com esse processo, a autora defende a educação intercultural, pois ela pode contribuir para que a interação e o reconhecimento entre as culturas ocorra, valorizando os conhecimentos e experiências dos alunos e afirmando suas identidades, especialmente as que foram apagadas ou negadas pela escola, porque pautada em um currículo monocultural.

A educação intercultural não busca a diluição das diferenças, nem somente o que há de comum entre elas. A pretensão é que permaneçam em "ebulição", em "tensão", para que seja possível mudar as relações de poder. Dessa forma, "[...] as diferenças não se diluem imediatamente num caldo comum, nem são hierarquizadas, tratadas como superiores ou inferiores, melhores ou piores, mas permanecem em tensão, em ebulição" (AZIBEIRO E FLEURI, 2012, p. 225).

A educação intercultural, além disso, enfatiza a relação entre os sujeitos - diferentes - e a possibilidade de termos compreensões diferentes sobre as coisas, sobre a vida, sobre os valores, sobre a educação. Ela defende a produção plural de sentidos, pois os significados podem ser reelaborados nos processos de interação cultural, em um contexto relacional, que possibilita 0 reconhecimento da diversidade de conhecimentos.

Como afirma Candau (2011), na educação intercultural, se não se aceitarem as possibilidades da emergência do plural, do dissenso, do múltiplo, do divergente, do diverso, do diferente, serão reprimidas e excluídas as vozes dissonantes. Ainda segundo a autora, apesar de nos últimos anos a sensibilidade para com a diferença ter aumentado entre os professores, ainda há muito por ser feito para que ela seja trabalhada de modo a contribuir para com a criação de outras relações entre os sujeitos e as culturas, evitando as formas estereotipadas de lidar com a diferença.

Cabe destacar também que a dificuldade de trabalhar a diferença aumentou no contexto pós 2016, com o golpe e a chegada de um projeto conservador ao poder, conservadorismo esse intensificado em 2019. Trabalhar a diferença tornou-se motivo de perseguição, ameaça e, nos casos de professores não concursados, pode significar a perda do emprego. Por isso, a educação intercultural tem o grande desafio de manter-se viva nesse contexto tão adverso, mostrando a potência da diferença e do diálogo permanente entre sujeitos diferentes, bem como a importância da defesa das diferentes modalidades de justiça. A educação intercultural afirma a "[...] diferença como riqueza. Promove processos sistemáticos de diálogo entre diversos sujeitos - individuais e coletivos -, saberes e práticas 
na perspectiva da afirmação da justiça - social, econômica, cognitiva e cultural." (CANDAU, 2014a, p. 1).

Isso nos permite dizer que ela continuará viva, apesar do contexto de um governo de extrema direita, porque, por suas características, incluindo a crítica radical ao sistema capitalista, sempre foi do campo da resistência, da luta, da contestação, da subversão. Sempre colocou em xeque as relações de poder estabelecidas. Tem uma experiência histórica de luta que a potencializa e a alimenta nestes tempos sombrios e de ataque sistemático aos grupos diferentes, notadamente, negros, indígenas e LGBTs+. Da mesma forma, a existência de propostas alternativas, isto é, de projetos interculturais em curso, em diferentes contextos, continuará mostrando as possibilidades de construção de uma educação não racista e não discriminatória.

\section{ANÁLISE DA PERCEPÇÃO DOS PROFESSORES}

Iniciamos destacando que a escola onde os professores entrevistados atuam se localiza no Assentamento Tamarineiro I, s/n, na zona rural da cidade de Corumbá (MS). A escola funciona em período integral, atendendo alunos de Educação Infantil, Ensino Fundamental I e Ensino Fundamental II. Embora a escola esteja localizada na zona rural e seja de tempo integral, essas especificidades não serão contempladas neste artigo. Aqui, faremos referência a seis professores, que serão identificados por pseudônimos para manter seu anonimato, conforme o quadro a seguir (Quadro 1):

Quadro 1 - Informações básicas dos professores entrevistados.

\begin{tabular}{|l|l|c|c|}
\hline Professor & \multicolumn{1}{|c|}{ Atuação } & Licenciatura & Anos na escola \\
\hline Severina & Ensino Fundamental I e II & Educação Física & 6 \\
\hline Maria & Ensino Fundamental I & Pedagogia & 30 \\
\hline Pedro & Ensino Fundamental I e II & Educação Física & 5 \\
\hline Sílvia & Ensino Fundamental I & Pedagogia & 45 \\
\hline Bernardo & Ensino Fundamental I & Letras/Espanhol & 2 \\
\hline Laura & Ensino Fundamental II & Letras/Inglês & 2 \\
\hline
\end{tabular}

Fonte: Próprio autor.

Os professores foram entrevistados individualmente no ambiente de seu trabalho, durante suas horas atividades. As entrevistas foram gravadas, transcritas na íntegra e analisadas segundo a ótica da interculturalidade. Salientamos que as entrevistas têm sido vistas nas ciências sociais e, de modo específico, na educação como uma forma privilegiada de obter os dados para o alcance dos objetivos da pesquisa, pois "[...] caracterizam-se pelo facto de os sujeitos estarem à vontade e falarem livremente sobre os seus pontos de vista [...]. As boas entrevistas produzem uma riqueza de dados, recheados de palavras que revelam as perspectivas dos respondentes" (BOGDAN E BIKLEN, 1994, p. 136).

Feitas as observações sobre os procedimentos metodológicos e sobre a escola, vale apontar que a educação no contexto da fronteira é muito importante para construir relações entre os países e, além de trocas culturais, pode gerar desenvolvimento para ambos. Por outro lado, a desconsideração da "[...] realidade sociocultural dos países vizinhos fomenta preconceitos, visões e opiniões parciais quando não distorcidas - de alguns países em relação aos outros. Dificultam - quando não inibem as relações bilaterais, multilaterais e os projetos de cooperação." (PEREIRA, 2014, p. 95). 
Ainda que as relações ocorram nas fronteiras, sejam essas de preconceito ou colaboração, cabe salientar que na ótica da interculturalidade intenta-se que elas ocorram sem as visões estereotipadas e preconceituosas. Espera-se que as relações sejam construídas sob a ótica dos subalternizados, por meio de laços de solidariedade com vistas à justiça social e ao respeito à diversidade cultural.

Considerando que o artigo se pauta na perspectiva intercultural, portanto, contrária a toda forma de discriminação e preconceito, necessário se faz explicitar que, embora utilizemos o termo genérico bolivianos para todos os alunos da Bolívia que frequentam a escola onde os professores entrevistados trabalham, sabemos que esse termo é uma simplificação e não corresponde à diversidade étnica e cultural, nem de gênero, classe e crença, que compõe o conjunto do que será por ele denominado.

Como apontam Souchaud e Baeninger (2008, p. 271), o processo migratório boliviano para Corumbá, no Mato Groso do Sul, é muito antigo, "[...] mas que revela - atualmente em seus fluxos - novas conformações, composições e redes denotando perfis socioeconômicos e culturais diferenciados no âmbito do próprio contingente de migrantes bolivianos". Além disso, há uma questão indígena: efetivamente, em sua grande maioria, os alunos bolivianos são indígenas:

a identidade na fronteira Brasil-Bolívia pode ser problematizada não apenas por critérios de nacionalidade (brasileiros/ bolivianos), mas também por critérios étnicos (índios/ não índios). Há uma dupla alteridade do boliviano em solo brasileiro: ao mesmo tempo em que é visto como um "outro" nacional (estrangeiro), é representado como um "outro" indígena, duplicando, em grande medida, o estigma social que recai sobre o grupo. Grande parte dos migrantes e residentes bolivianos na fronteira tem, de fato, sua origem nos Aymara ou nos Quéchua (do altiplano), além dos Kambas e dos Chiquitanos, das terras baixas. (COSTA, 2015, p. 38).

Como já afirmamos, mesmo que o fato de a maioria ser de indígenas traga também um componente de discriminação étnica, em nossa pesquisa, o foco foi em sua nacionalidade diferente.

O contexto da fronteira traz algumas especificidades para a educação que costumam ser vistas como um problema, como algo que prejudica a aprendizagem. Por tratar-se de países com línguas oficiais diferentes - português e espanhol -, os estudantes bolivianos, falantes da língua espanhola, são vistos como alunos que têm dificuldades de aprendizagem. O Brasil, por fazer fronteira com vários países de língua espanhola e de várias línguas indígenas, produz diversas possibilidades para a interculturalidade, mas elas tendem a ser vistas como uma dificuldade a mais no processo educativo. Há, efetivamente, uma heterogeneidade linguística nas regiões fronteiriças, como é o caso da escola onde os sujeitos de nossa pesquisa atuam:

[...] nossas fronteiras são marcadas por uma heterogeneidade linguística, iniciandose ao norte, onde há esse contato entre as diferentes nações indígenas, o português e o espanhol, apresentando uma clara situação de plurilinguismo, até a região oeste, onde as fronteiras brasileiras são também marcadas pelo convívio das línguas portuguesa e espanhola com as línguas indígenas da Bolívia e do Paraguai. (STURZA, 2005, p. 48, grifos nossos).

Na educação, nas escolas situadas nas fronteiras do Brasil, comumente ocorrem diálogos bilíngues. Não raras vezes, esse bilinguismo é mais informal, no sentido de ocorrer nas conversas entre alunos, e não como estratégia pedagógica. As escolas brasileiras, porque fundadas na perspectiva monocultural, tendem a utilizar somente a língua portuguesa, forçando os alunos bolivianos, considerados em nossa pesquisa, a aprenderem o português. A proximidade geográfica, que produz um encontro de culturas, acaba se tornando um espaço de imposição de uma língua, no caso, a 
portuguesa. Uma realidade peculiar e rica torna-se um espaço de apagamento da língua e, em consequência, de apagamento de identidades.

Portanto, a língua pode ser um fator de exclusão nas escolas situadas na fronteira. Os professores entrevistados nesta pesquisa mostram que a dificuldade da língua é muito comum e prejudica a aprendizagem dos alunos: "Quanto aos alunos da pré-escola, eles têm a dificuldade da linguagem, até eles aprenderem o português" (Professora Severina).

Com Fleuri (2003, p. 20), lembramos que "[...] vários estudos constatam, a partir da década de 1960, o baixo rendimento escolar entre crianças com língua materna distinta da empregada no sistema escolar oficial". Entretanto, na perspectiva da interculturalidade, a questão não passa pela exigência de o aluno boliviano aprender o português para que consiga aprender. Muito mais interessante seria a escola aproveitar a existência da diversidade linguística para que tanto os alunos portugueses e quanto os alunos bolivianos pudessem aprender as duas línguas. Isso tornaria o processo educativo muito mais rico e ampliaria a aprendizagem. Na perspectiva da interculturalidade, o desafio no processo educativo é considerar cada realidade, com base na valorização das culturas e línguas presentes na escola, sem que a "mistura" seja vista como problema.

Assim como a professora Severina, a professora Maria também vê a língua diferente como um problema: "Em relação à aprendizagem, a maior dificuldade que a gente encontra é em relação à linguística deles. Na sala de aula, muitas vezes, eles misturam o português com o espanhol na hora de escrever ou mesmo na hora de falar".

De modo semelhante às duas professoras citadas, o professor Pedro deixa claro que os alunos bolivianos têm dificuldade com a língua no início, mas aos poucos vão se adaptando e participando como os demais alunos. Isso demonstra que se espera que o aluno boliviano de fato se dispa de sua língua e cultura, tornando-se um "igual" ou, na expressão de Skliar (2003), o "mesmo" - ou seja, espera-se que se "normalize", que se faça com que sua diferença despareça:

Em relação à aprendizagem, a princípio, os alunos estrangeiros encontram dificuldade em relação à linguagem assim que eles ingressam na escola. Após o período de adaptação, com o tempo, eles frequentam a aula e participam de forma harmoniosa como qualquer outro aluno. (Professor Pedro).

Temos ainda a fala da professora Sílvia, mostrando que o domínio da língua espanhola representa uma dificuldade para os alunos bolivianos, sem que haja preocupação em desenvolver uma pedagogia que venha ao encontro dessa diferença. Ou o aluno aprende a língua portuguesa, ou não vai conseguir aprender. Disse a professora: "Na aprendizagem, a dificuldade é a língua espanhola, e eles escrevem tudo em espanhol".

O que a escola tenta fazer, como é possível perceber pelas falas dos professores até aqui citados, é ignorar e apagar a diferença, fazer com que o aluno deixe de utilizar o espanhol e aprenda o português. Segundo Skliar (2003), a escola não olha o outro como outro, não se pauta nas diferenças, considera todos como iguais e, se não são iguais (e nunca são!), age como se fossem e espera que se tornem iguais, os mesmos. Desse modo, a escola acaba por normalizar os alunos. Trata-se, segundo o autor, de uma pedagogia que abriga, hospeda, mas não se preocupa com o seu hóspede, isto é, aceita que o aluno esteja na escola, mas não se preocupa com ele, com sua diferença. 
Essa prática insere e inclui o aluno no sentido de "colocar dentro" de uma mesmice. A escola acaba por impor a língua portuguesa como a "oficial" e a língua espanhola como diferente, que dificulta a aprendizagem e aos poucos é excluída e eliminada, mesmo que os seus falantes residam em um país onde a língua oficial é a espanhola e que eles a utilizem na comunicação informal em sua família e comunidade. Com isso, desenvolve um poderoso processo de normalização, de homogeneização, o que produz também exclusão, discriminação, subalternização.

Não estão sendo colocadas em xeque as boas intenções dos professores em quererem que seus alunos aprendam a língua portuguesa para que sejam bem-sucedidos na escola. O que se está mostrando é que, ao fazê-lo, apesar da boa intenção, os professores acabam desenvolvendo, como aponta Skliar (2002), uma pedagogia que nega a existência do outro em sua diferença, procurando torná-lo normal, o mesmo:

No movimento de deslocamento da perspectiva que nega a existência do outro para a que o marca, mantemos, também na formação de educadores e educadoras, a dicotomia normal versus anormal, porém, evidenciando a existência do diferente, construindo um acúmulo de conteúdos sobre o outro, definindo-o, identificando-o e o encerrando em um opaco envoltório tecnicista. (SKLIAR, 2002, p. 22).

Podemos dizer que os professores pensam dessa forma porque são um efeito de uma sociedade monocultural, colonial e homogeneizadora, que tende a ver na diferença um "problema" que tende a não desaparecer, por maiores que sejam as tentativas de eliminá-lo: "o outro é o outro gênero, o outro é a cor diferente, o outro é a outra sexualidade, o outro é a outra raça, o outro é a outra nacionalidade, o outro é o corpo diferente". (SILVA, 2013, p. 97, grifos nossos).

A escola não oferece uma diversidade de pedagogias, sobretudo não desenvolve a pedagogia da diferença. Arroyo (2012) salienta que não faz sentido pensar em apenas uma pedagogia; precisamos de várias pedagogias, haja vista a diversidade de sujeitos que frequentam as escolas. Portanto, em qualquer processo educativo, a pedagogia não pode ser uma só - precisa-se considerar os processos históricos dos sujeitos e suas culturas. Na complexa dinâmica escolar em contextos fronteiriços, não há a possibilidade de uma única pedagogia:

A diversidade de movimentos sociais aponta que não podemos falar de uma única pedagogia, nem estática nem em movimento, mas de pedagogias antagônicas construídas nas tensões políticas, sociais e culturais de dominação/subordinação e de resistência/afirmação de que eles participam. Todas as pedagogias fazem parte dessa relação política conflitiva de dominação/reação/libertação. (ARROYO, 2012, p. 15).

Essa diversidade de pedagogias faz falta na escola da fronteira Brasil-Bolívia. Os professores, com o intuito de fazer com que os alunos aprendam, entendem que é necessário que aprendam a língua portuguesa. Utilizam a mesma pedagogia que utilizariam em qualquer outra escola. Isso ocorre porque "a cultura escolar dominante em nossas instituições educativas, construída fundamentalmente a partir da matriz político-social e epistemológica da modernidade, prioriza o comum, o uniforme, o homogêneo, considerados como elementos constitutivos do universal". (CANDAU, 2011, p. 241).

Em função dessa cultura dominante, as diferenças, tão presentes nas escolas, costumam ser ignoradas no processo educativo. Apesar de as diferenças sempre existirem na escola, continuam não sendo reconhecidas ou consideradas. Elas tendem a ser apagadas. Devem desaparecer para que a aprendizagem possa ocorrer. Elas continuam, muitas vezes, sendo percebidas como "desvios", como anormalidade diante de pressupostas características essenciais, universais, únicas, como se 
todos os alunos fossem os mesmos. Assim, produz-se a negação de todos os que não tiverem essas características. Conforme Marques:

A negação refere-se ao fato de não se trabalhar explicitamente a questão das diferenças. $O$ que se busca é a compreensão de um universal calcado na essência da existência humana, no qual são levadas em conta quaisquer características individuais e/ou grupais numa homogeneidade simplória e ideologicamente excludente. São os casos das filosofias e pedagogias essencialistas, que falam de traços gerais e, por isso mesmo, de sentido único e universal. (MARQUES, 2012, p. 103).

Há de se destacar também que, apesar da tendência de os professores entenderem que a língua espanhola atrapalha a aprendizagem, há professores que se situam fora da lógica da homogeneização e desenvolvem práticas que valorizam a diferença presente na escola. Essas atitudes colaboram para que os alunos bolivianos não sejam tão excluídos. O professor Bernardo, na entrevista, expressou sua preocupação em estabelecer uma conversa com os alunos bolivianos, recorrendo ao espanhol e mostrando que também aprende com eles: "No início, eles tinham dificuldades em relação à língua portuguesa porque eles confundiam muito o espanhol com o português, mas, devido à interação, às vezes, eu falo em espanhol e aprendo com eles".

Como se percebe, o professor parte do reconhecimento da diferença e, ao reconhece-la, potencializa a aprendizagem, o que vem ao encontro do que Candau (2014, p. 32) recomenda: "que as práticas educativas partam do reconhecimento das diferenças presentes na escola e na sala de aula". Também merece destaque a ideia manifestada pelo professor de que ele aprende com os alunos. Colocar-se na condição de quem aprende com os alunos é de suma importância no processo educativo, segundo a ótica intercultural, pois é uma forma concreta de colocar em xeque as hierarquias historicamente construídas e naturalizadas.

Além disso, ao mostrar-se interessado em falar a língua de seu aluno, o professor evidencia que ela é importante, produzindo no aluno uma sensação de que sua forma de falar não é inferior, mas apenas diferente. Com isso, pode-se perceber que a escola não precisa necessariamente normalizar o aluno, não precisa reforçar a ideia de superior versus inferior, capaz versus incapaz. A escola pode valorizar a língua do aluno, sua cultura, sua identidade. Pode-se dizer que o professor, ao agir dessa forma, mostrando-se interessado em falar a língua do aluno e aprender com ele, se aproxima de um agir intercultural, pois:

Agir interculturalmente requer diálogo e compreensão mútua dos vários pontos de vista, de um lado e de outro. Seu objetivo é promover a unidade e a relação entre distintos grupos, sujeitos e culturas, de maneira que tal unidade e tal relação não anulem as diferenças, mas que sejam potencializadores do desenvolvimento de cada um. (COPPETE, 2012, p. 213214).

Falar com o aluno recorrendo à sua língua potencializa-o, mas o professor também se potencializa, pois aprende com o aluno. Nesse encontro, as culturas modificam-se, assim como os sujeitos, vindo ao encontro do que a interculturalidade defende: que é na diferença que se aprende, e não na repetição do mesmo.

Uma questão que chama a atenção é que, na escola onde os professores entrevistados atuam, com muitos alunos bolivianos, não há sequer a disciplina de Língua Espanhola no currículo, que poderia ser um espaço/tempo importante de afirmação da identidade e da cultura dos sujeitos bolivianos. Ao invés da Língua Espanhola, no currículo, há a disciplina de Língua Inglesa. Lembramos com Marin 
(2009, p. 9) que "a escola oficial se encarregou de transmitir a visão de mundo, a língua e a cultura dominantes, sendo uma instituição eficaz no seu objetivo de reduzir, denegrir e marginalizar as línguas, as visões de mundo e os conhecimentos ou saberes locais". Em um contexto de fronteira, onde as duas línguas faladas são português e espanhol, privilegiar a língua inglesa parece indicar que a escola não só assumiu o papel de marginalizar as línguas e impor a visão de mundo dominante, como também continua a desempenhá-lo. Ainda segundo Marin (2009, p. 14), "[...] a imposição do inglês como língua veicular empobrece as culturas e as línguas locais".

Entretanto, paradoxalmente, ainda que a disciplina de Língua Inglesa esteja no currículo, e não a de Língua Espanhola, ela acaba sendo um espaço/tempo no qual os alunos bolivianos não apresentam as "dificuldades" de aprendizagem relatadas pelos demais professores. Conforme a fala da professora Laura: "Quanto à aprendizagem, eu percebo que, na matéria de Inglês, na prática, é bem mais fácil, se comparado aos outros alunos. $O$ inglês para eles é melhor desenvolvido por serem de fronteira".

A fala dessa professora permite-nos fazer várias observações. Em primeiro lugar, novamente, percebe-se que a escola tem como cultura lidar com os alunos como se fossem iguais; quando essa igualdade parece ocorrer em certo sentido, a aprendizagem acaba acontecendo com maior facilidade. No caso, a "igualdade" dá-se pelo fato de nem os bolivianos, nem os brasileiros saberem a língua inglesa. Nessa situação, aquilo que é visto como uma dificuldade para os demais professores (o não domínio da língua portuguesa) acaba desaparecendo, pois o domínio do português não faz diferença para a aquisição da língua inglesa, podendo tornar-se, inclusive, uma vantagem estar em um contexto de fronteira, especialmente pela cultura da existência de mais de uma língua.

Outra observação a ser feita, que vem ao encontro de nossa argumentação, é que os alunos bolivianos efetivamente não têm problema de aprendizagem. O problema está na dificuldade que a escola e os professores têm de ensinar a partir de diferentes pedagogias, isto é, de ensinar a partir da diferença, e não a partir da mesmidade.

Por fim, cabe ressaltar que, embora o inglês seja uma língua colonial e, no contexto atual, seja um dos meios pelos quais se procura impor uma cultura homogênea e negar a diversidade de línguas, na escola, acaba sendo um espaço/tempo no qual os alunos bolivianos são menos inferiorizados e menos associados a problemas de aprendizagem e a dificuldades.

Lembramo-nos de Hall (1997) quando afirma que um processo de homogeneização, por maior que seja, sempre acaba produzindo diferenças. Por maiores que sejam as tentativas de globalização e homogeneização, a diferença continua existindo. Mostra também que, mesmo em contextos colonizadores e de globalização, com uma estratégia colonizadora eficiente como a língua inglesa, há espaços outros, há experiências outras que são produzidas. Evidencia, enfim, que, mesmo que a globalização seja "[...] uma ameaça de uniformização cultural, que põe em perigo a preservação da diversidade cultural, despertando conflitos e recolhimentos identitários e nacionais, facilitando, assim, a emergência das inevitáveis consequências da intolerância e do racismo" (MARIN, 2009, p. 14), essa uniformização, a rigor, é sempre uma impossibilidade.

Com essas observações, não estamos nos colocando na defesa da língua inglesa nos currículos escolares, muito menos dizendo que ela é importante nas escolas localizadas nas regiões de fronteira. Apenas intencionamos mostrar que as estratégias de homogeneização estão sempre sujeitas a processos locais que fazem com que outros sujeitos sejam produzidos e que as diferenças continuem 
existindo. Não faz sentido negar que há o uso da língua inglesa como língua "universal" e como aparato tecnológico que

[...] tende a favorecer a transmissão para o mundo de um conjunto de produtos culturais estandardizados, utilizando tecnologias ocidentais padronizadas, apagando as particularidades e diferenças locais e produzindo, em seu lugar, uma "cultura mundial" homogeneizada, ocidentalizada. Entretanto, todos sabemos que as consequências desta revolução cultural global não são nem tão uniformes nem tão fáceis de ser previstas da forma como sugerem os "homogeneizadores" mais extremados. (HALL, 1997, p. 18).

Longe de ser uma postura ingênua, reconhecer que nas práticas notadamente coloniais (imposição da língua inglesa) há possibilidades decoloniais contribui para assinalar a resistência dos grupos que historicamente foram subalternizados. Efetivamente, a educação intercultural tem, como um de seus objetivos importantes, dar visibilidade à resistência dos grupos oprimidos. A interculturalidade

se preocupa também com a exclusão, negação e subalternização ontológica e epistêmico-cognitiva dos grupos e sujeitos racializados; com as práticas - de desumanização e de subordinação de conhecimentos - que privilegiam alguns sobre outros, "naturalizando" a diferença e ocultando as desigualdades que se estruturam e se mantém em seu interior. Mas, e adicionalmente, se preocupa com os seres de resistência, insurgência e oposição, os que persistem, apesar da desumanização e subordinação. (WALSH, 2009, p. 23, grifos nossos).

Nesse sentido, sublinhamos que ter bom desempenho na disciplina de Língua Inglesa, para os alunos bolivianos, por mais paradoxal que possa parecer, é uma forma de resistência, é uma maneira de dizer que são capazes, que sua língua não precisa ser um problema, que ela pode ser uma vantagem pedagógica.

\section{OBSERVAÇÕES FINAIS}

Pela pesquisa efetuada, pode-se dizer que a maioria dos professores percebe a diferença linguística como algo que dificulta a aprendizagem dos alunos bolivianos. Os professores entendem que, à medida que os alunos bolivianos aprendem a língua portuguesa, vão conseguindo acompanhar as aulas e aprender os conteúdos.

Embora a experiência dos professores subsidie esse entendimento, pois eles percebem que as dificuldades dos alunos bolivianos diminuem ao longo da escolarização, observa-se que, na perspectiva da interculturalidade, o caminho é outro: as diferenças, incluindo as de língua, poderiam ser potencializadas como uma riqueza pedagógica, como uma forma de alunos brasileiros e bolivianos aprenderem as duas línguas; portanto, uma escola bilíngue em escola de fronteira seria um projeto importante. A própria pesquisa traz elementos que corroboram esse argumento: os professores, como relataram alguns, quando falam em espanhol com seus alunos, criam uma proximidade com eles, 0 que, inclusive, melhora a aprendizagem e possibilita a troca de conhecimentos.

Pode-se intuir também que, apesar de a escola não ter como proposta a interculturalidade, há momentos em que esta acaba acontecendo, forjada pela presença expressiva de alunos bolivianos. Esses momentos apontam o quanto a educação seria mais significativa se fosse pautada na perspectiva intercultural, evitando processos de inferiorização e discriminação. 


\section{REFERÊNCIAS}

ARROYO, Miguel. Outros sujeitos, outras pedagogias. Petrópolis: Vozes, 2012.

AZIBEIRO, Nadir Esperança; FLEURI, Reinaldo Matias. Paradigmas interculturais emergentes na educação popular. In: DANTAS, Sylvia Duarte (Org.). Diálogos interculturais: reflexões interdisciplinares e intervenções psicossociais. São Paulo: Instituto de Estudos Avançados da Universidade de São Paulo, 2012. p. 219-245.

BOGDAN, Robert C.; BIKLEN, Sari Knopp. Investigação qualitativa em educação: uma introdução à teoria e aos métodos. Porto: Porto Editora, 1994.

CANDAU, Vera Maria. Concepção de educação intercultural. Rio de Janeiro: Editora PUC-Rio, 2014a.

CANDAU, Vera Maria Ferrão. Diferenças culturais, cotidiano escolar e práticas pedagógicas. Currículo sem Fronteiras, v.11, n.2, p.240-255, jul./dez. 2011.

CANDAU, Vera Maria Ferrão. Educação intercultural: entre afirmações e desafios. In: MOREIRA, Antônio Flávio Barbosa; CANDAU, Vera Maria Ferrão (Orgs.). Currículos, disciplinas escolares e culturas. Petrópolis: Vozes, 2014b. p. 23-41.

CANDAU, Vera Maria. Sociedade, cotidiano escolar e cultura(s): uma aproximação. Educação \& Sociedade, v. 23, n. 79, p. 125-161, ago.2002.

COPPETE, Maria Conceição. Educação intercultural e sensibilidade: possibilidades para a docência. Florianópolis: UFSC, 2012.

COSTA, Gustavo Villela Lima da. Os bolivianos em Corumbá-MS: conflitos e relações de poder na fronteira. Mana [online]. V. 21, n. 1, p. 35-63, 2015.

FLEURI, Reinaldo. Interculturalidade e educação. Revista Brasileira de Educação. São Paulo, n. 23, p. 16-35, Maio/Jun/Ago, 2003.

MARQUES, Luciana Pacheco. Cotidiano Escolar e Diferenças. Educação em Foco, Juiz de Fora, v.17, n.1; p. 101-117, mar/jun. 2012.

HALL, Stuart. A centralidade da cultura: notas sobre as revoluções culturais do nosso tempo. Educação e Realidade, Porto Alegre, v. 22, n. 2, p. 15-46, jul./dez. 1997.

MARIN, José. Interculturalidade e Descolonização do saber: relações entre saber local e saber universal, no contexto da globalização. Espaço Pedagógico, Chapecó, v.16, n.1, p.7-26, jan./jun. 2009.

NUNES, Flaviana Gasparotti. Interculturalidade e o papel da escola na atualidade: reflexões a partir do filme Entre os muros da escola. Pro-Posições, Campinas, v. 22, n. 3, v66, p. 113-129, set./dez. 2011.

PEREIRA, Jacira Helena do Valle. Educação na fronteira: o caso Ponta Porã (MS) e Pedro Juan Caballero (PY). Revista Papéis, Campo Grande, v. 18, n. 36, p. 93-106, 2014.

SANTOS, Boaventura de Sousa. Para um novo senso comum: a ciência, o direito e a política na transição paradigmática, São Paulo: Cortez, 2002. 
SILVA, Tomaz Tadeu da (Org.). A produção social da identidade e da diferença. In: SILVA, Tomaz Tadeu da. Identidade e diferença: a perspectiva dos Estudos Culturais. Petrópolis: Vozes, 2013, p. $73-102$

SKLIAR, Carlos. A educação que se pergunta pelos outros: e se o outro não estivesse aqui?. In: LOPES, Alice Casimiro; MACEDO, Elizabeth Macedo (Org.). Currículos: debates contemporâneos. São Paulo: Cortez, 2002, p. 196-202.

SKLIAR, Carlos. Pedagogia (improvável) da diferença: e se o outro não estivesse aí? Rio de Janeiro: DP\&A, 2003.

SOUCHAUD, Sylvain; BAENINGER, Rosana. Collas e cambas do outro lado da fronteira: aspectos da distribuição diferenciada da imigração boliviana em Corumbá, Mato Grosso do Sul. Revista Brasileira de Estudos da População. São Paulo, v. 25, n. 2, p. 271-286, jul./dez. 2008.

STURZA, Eliana Rosa. Línguas de fronteira: o desconhecido território das práticas lingüísticas nas fronteiras brasileiras. Ciência e Cultura, v. 57, n. 2, p. 47-50, abr./jun. 2005.

WALSH, Catherine. Interculturalidade crítica e pedagogia decolonial: in-surgir, re-existir e re-viver. In: CANDAU, Vera Maria (Org). Educação Intercultural na América Latina: entre concepções, tensões e propostas. Rio de Janeiro: 7 Letras, 2009. p.12 a 43. 